\title{
Immunity to hepatitis A virus among working professionals in Poland - Results of a 3-year serological survey 2013-2015
}

\author{
Grzegorz Juszczyk ${ }^{1, A-F}$, Aleksandra Izabela Czerww ${ }^{2,3, C-F}$, Bożena Walewska-Zielecka',E-F, \\ Marcin Mikos ${ }^{4, E-F}$, Tomasz Banaśs,E-F, Andrzej Deptała ${ }^{6, E-F}$, Janusz Ślusarczyk ${ }^{7, A, D-F}$ \\ ${ }^{1}$ Department of Public Health, Medical University, Warsaw, Poland \\ ${ }^{2}$ Department of Health Economics and Medical Law, Medical University, Warsaw, Poland \\ ${ }^{3}$ Department of Economic and System Analysis, National Institute of Public Health - NIH, Warsaw, Poland \\ ${ }^{4}$ Department of Medicine and Health Sciences, Modrzewski Academy, Kraków, Poland \\ ${ }^{5}$ Department of Gynecology and Oncology, Jagiellonian University Medical College, Kraków, Poland \\ ${ }^{6}$ Department of Cancer Prevention, Medical University, Warsaw, Poland \\ ${ }^{7}$ National Institute of Public Health, Warsaw, Poland \\ A - Research concept and design, B - Collection and/or assembly of data, C - Data analysis and interpretation, \\ $D$ - Writing the article, E - Critical revision of the article, F - Final approval of article
}

\begin{abstract}
Juszczyk G, Czerw Al, Walewska-Zielecka B, Mikos M, Banaś T, Deptała A, Ślusarczyk J. Immunity to hepatitis A virus among working professionals in Poland - Results of a 3-year serological survey 2013-2015. Ann Agric Environ Med. 2018; 25(3): 572-575. doi: 10.26444/aaem/91467
\end{abstract}

\begin{abstract}
Introduction. Hepatitis A (HA) is caused by infection with the hepatitis A virus (HAV). The differential etiological diagnosis of acute hepatitis is based on a positive result of the serological test detecting IgM class anti-HAV. For epidemiological studies on past infection and seroprevalence of HAV in populations, the tests measuring IgG class anti-HAV or total anti-HAV are used. Since the 1990s, specific prophylaxis is possible by vaccination against HA. In Poland, vaccination is recommended and in majority is performed at own cost.

Materials and method. Database was obtained from electronic medical records of the 2 major private health care providers networks (Luxmed and Medicover) operating in Poland. During a 3-year period (2013-2015), 1,124 persons with unknown status of anti-HA vaccination were tested for the presence of total anti-HAV.

Objective. The aim of the study was to evaluate the seroprevalence of anti-HAV among working professionals in Poland. Results. Anti-HAV were detected in 603 (53.6\%) persons, while 521 (46.3\%) tested negative. The study group was divided into 2 subgroups: 25-44 and 45-64-years-old. For detailed statistical analysis, the presence of anti-HAV was considered as a dependent variable, and its predictors were gender, age and the year of the test performance. The presence of anti-HAV was significantly more prevalent in older age group. The lack of specific antibodies was more prevalent in younger age group.

Conclusions. Results of the study show increasing susceptibility to HAV infection in the younger age group, compared with the older age group of corporate professional employees in large cities in Poland. Since the epidemiological situation of HA is currently changing with increasing number of symptomatic cases of $\mathrm{HA}$, it is suggested that employers might consider including an additional procedure of vaccination against $\mathrm{HA}$ into their private health insurance portfolio.
\end{abstract}

- Key words

hepatitis $A$, hepatitis $A$ antibodies seroprevalence, vaccination against hepatitis type $A$

\section{INTRODUCTION}

Hepatitis A (HA) is caused by infection with the hepatitis A virus (HAV). The virus belongs to family Picornaviridae and genus Hepatovirus, is non-enveloped, has an icosahedral appearance with a diameter of $27 \mathrm{~nm}$, and inside the virion there is a single-stranded RNA. Seven HAV genotypes were described and of these, 4 may infect humans [1]. The virus was visualized for the first time in stool specimens by immune electron microscopy in 1973 by Feinstone et al. [2] The occurrence of HAV infection is routinely diagnosed serologically by detection of specific anti-HAV in a serum sample. In a study on the class-specific immune response in symptomatic patients admitted to a hospital with acute HA,

Address for correspondence: Aleksandra Izabela Czerw, National Institute of Public Health, Poland, Warsaw, Zwirki i Wigury, 08-456 Warsaw, Poland e-mail: aczerw@pzh.gov.pl

Received: 08.03.2018; accepted: 22.05.2018; first published: 25.09.2018 in all of them had IgA and IgM anti-HAV detected, while IgG anti-HAV was detectable in $37 \%$ of them. IgG anti-HAV became detectable in all the patients beginning from the third week after admittance [3]. At present, for routine differential diagnosis of acute hepatitis cases, the presence of IgM-anti$\mathrm{HAV}$ proves etiology of $\mathrm{HA}$, while for epidemiological studies on past infection, mainly the tests measuring IgG anti-HAV or total anti-HAV are used.

HA occurs worldwide in the form of sporadic cases or epidemic outbreaks. HAV is transmitted by the faecaloral route, by person-to-person contact, or ingestion of contaminated food or water. A number of studies on the possibility of infection with HAV among blood or blood products recipients, or haemodialysed patients, have not confirmed that such procedures may be relevant in HAV transmission. Blood transfusion from donors who were symptomless for hepatitis, but where the transmission of HAV occurred were just casuistic $[4,5]$. Nevertheless, 
a study from Latvia showed that a community outbreak comprising 2,800 cases of HA after blood transfusion did occur [6]. Transplacental transmission of HAV has not been reported [7].

Currently, infection with HAV - both symptomatic and asymptomatic - is predominant in developing countries with poor sanitary and hygienic conditions. Risk groups for acquiring HAV infection among people living in developed countries are health care workers taking care of both children and adults, people living in overcrowded situations, and close personal contacts, e.g. soldiers or prisoners, workers maintaining sewage systems, and travelers to tropical countries. For a number of years, due to multiple outbreaks of HA among men who have sex with men (MSM), that group is also considered at risk of HAV infection [8]. An important source of epidemic outbreaks could also be associated with frozen food which, due to the global trade of potentially contaminated products, may be responsible for multi-country outbreaks of HAV infection [9]. However, the possibility of prophylaxis against HA has become possible since the 1990s when specific vaccines were marketed [10]. At present, vaccination against $\mathrm{HA}$ is performed in some countries on a mass scale, in other countries the vaccine is offered on demand to individual persons or to people exposed to HAV due to their work.

\section{OBJECTIVE}

The aim of the study was to evaluate the seroprevalence of anti-HAV among working professionals in Poland. The professionals were predominantly living in large Polish cities and working in corporate companies which provided them with private health insurance and access to private health care providers.

\section{MATERIALS AND METHOD}

Database was obtained from electronic medical records of 2 major private health care providers networks (LUXMED and MEDICOVER) operating in Poland. Both providers operate in 11 of 16 capitals of administrative regions (Voivodships). All the employees had private health insurance covered by their employer, in addition to health insurance guaranteed by the State. Inclusion criteria were as follows: a person had access to a general practitioner; her/his status of vaccination against HAV was unknown; have had the serological test detecting total anti-HAV performed, as referred by the physician within the study period. Data entailed anonymized information on a unique patient identifier, age, gender, year when the test was performed (year of test), and test results (positive or negative).

During a 3-year period (2013-2015), 1,124 persons were tested for the presence of total anti-HAV. Testing was performed in VIDAS automatic immunoanalyzer (BioMerieux).

\section{RESULTS}

The study group consisted of persons between the ages of 25 $64($ mean $=38.79 ; \mathrm{SD}=9.71), 536$ of them were women $(47.7 \%)$ and 588 (52.3\%) were men. Both gender groups had similar age distribution. The majority of tests were performed in 2013 $(\mathrm{n}=514 ; 45.7 \%)$ and $2014(\mathrm{n}=411 ; 36.6 \%)$, while in 2015,199 tests $(17.7 \%)$ were registered. Anti-HAV were detected in 603 (53.6\%) persons, while 521 (46.3\%) persons tested negative.

Presence of anti-HAV was considered as a dependent variable, and its predictors were gender, age and year of the test performance. Logistic regression analysis was applied in order to evaluate the main effects of those predictors and interactions among them. Firstly, the model that comprised all predictors and all possible interactions was analysed. In further models, the number of interactions was limited, starting from the most and moving to less saturated. Table 1 presents the regression coefficients obtained for the first model with all predictors and interaction effects.

Table 1. Regression coefficient - saturated model

\begin{tabular}{lcccc}
\hline Predictors & B & Wald & df & $p$ \\
\hline Gender & -17.27 & 0.01 & 1 & 0.960 \\
\hline Age & 0.05 & $26.78^{* *}$ & 1 & 0.001 \\
\hline Year of test & -0.06 & 0.24 & 1 & 0.627 \\
\hline Gender * Year of test & 0.01 & 0.00 & 1 & 0.963 \\
\hline Year of test * Age & 0.01 & $87.06^{* *}$ & 1 & 0.001 \\
\hline Gender * Age & 0.03 & $4.42^{*}$ & 1 & 0.035 \\
\hline Gender * Year of test * Age & 0.01 & $4.44^{*}$ & 1 & 0.035 \\
\hline${ }^{*}-\mathrm{p}<0,05 ;{ }^{*}-\mathrm{p}<0.01$ & & & &
\end{tabular}

Outcomes were statistically significant and showed a relationship between the anti-HAV results and age of the tested persons $(\mathrm{OR}=1.05)$. Presence of anti-HAV was more prevalent in the group of older participants. There were also significant interactions between: year of test and age, gender and age. Also, the second-order interaction among gender and year of test and age was statistically significant. Interaction means that the relationship between 2 variables is modified by another variable or variables. The second-order interaction in this instance can be interpreted in terms of the effect that the age of participants influenced the relationship between the anti-HAV results and gender, and in terms of possible differences in this effect, between the results acquired in 2013 and in the 2014-2015 period.

In order to analyse differences between the younger and older working professionals, the study group was divided into 2 subgroups: $25-44$ and 45-64-years-old. Table 2 summarizes the distribution of anti-HAV results in those groups.

Table 2. Distribution of anti-HAV seroprevalence in younger and older working professionals

\begin{tabular}{lcccccc}
\hline \multicolumn{7}{c}{ Test results } \\
\hline Age group & \multicolumn{2}{c}{$\begin{array}{c}\text { Anti-HAV } \\
\text { positive }\end{array}$} & \multicolumn{2}{c}{$\begin{array}{l}\text { Anti-HAV } \\
\text { negative }\end{array}$} & \multicolumn{2}{c}{ Total } \\
\hline $25-44$ & $\mathrm{n}$ & $\%$ & $\mathrm{n}$ & $\%$ & $\mathrm{n}$ & $\%$ \\
\hline $45-64$ & 407 & 47.8 & 445 & 52.2 & 852 & 100 \\
\hline Total & 196 & 72.1 & 76 & 27.9 & 272 & 100 \\
\hline & 603 & 53.6 & 521 & 46.4 & 1,124 & 100 \\
\hline
\end{tabular}

Pearson's chi-squared test $\chi^{2}$ proved the relationship between age group and anti-HAV seroprevalence to be statistically significant $\left(\chi^{2}(1)=48.91 ; \mathrm{p}<0.001\right)$. In the 
older group of participants aged $45-64$, the anti-HAV seroprevalence was substantially higher.

In order to interpret the second-order interaction, the study groups were finally divided into 2 subgroups, according to the year of test -2013 and 2014-2015. Table 3 presents regression coefficients obtained in the regression models concerned with relationship between gender and HAV seroprevalence in the 2 age groups, depending on the year of study.

Table 3. Results obtained in the regression models concerned with relationship between gender and HAV seroprevalence in the 2 age groups, depending on the year of study

\begin{tabular}{lccccc}
\hline Group & B & OR & Wald & df & $P$ \\
\hline Age group 25-44 (2013) & -0.46 & 0.63 & $5.13^{*}$ & 1 & 0.023 \\
\hline Age group 45-64 (2013) & 0.21 & 1.26 & 2.37 & 1 & 0.123 \\
\hline Age group 25-44 (2014-2015) & -0.25 & 0.78 & 1.80 & 1 & 0.179 \\
\hline Age group 45-64 (2014-2015) & -0.06 & 0.94 & 0.03 & 1 & 0.867 \\
\hline
\end{tabular}

$\mathrm{B}$ - unstandardized regression coefficients; OR - odds ratio; Wald - Wald test; $\mathrm{df}$ - degrees of freedom; $p$ - statistical significance; ${ }^{*} \mathrm{p}<0.05$

In the 25-44 age group in the study conducted in 2013, there was a statistically significant relationship between gender and HAV seroprevalence. Presence of anti-HAV was more prevalent in the group of women aged 25-44 years tested in 2013, than in the group of men aged 25-44 tested in the same year. According to Cox and Snell, the $\mathrm{R}^{2}$ measure percent of variance accounted for $1.3 \%$. This means that $1.3 \%$ differences between participants in terms of being anti-HAV positive or anti HAV negative can be ascribed to gender.

There were no statistically significant relationships in the other 3 subgroups.

\section{DISCUSSION}

HA is usually a self-limiting disease in a large part of cases with asymptomatic course; however, both symptoms and severity of illness might be age-related. In children, it is mostly asymptomatic, but adults are more likely to present clinical symptoms. HAV infection in adults results in significant morbidity, hospitalizations, and sometimes mortality if HA ends in fulminant hepatitis. The normalization of biochemical liver function test may take several weeks or months [10].

A major breakthrough in the prophylaxis of HA was the marketing of efficient vaccines [11]. The WHO states that in a relatively large proportion of the adult population living in countries with diminishing HA endemicity, susceptibility to $\mathrm{HAV}$ is growing, and large-scale vaccination is likely to be cost-effective [10].

For employers, HA in the adult working population is connected with absenteeism $[12,13]$. Immunity against $\mathrm{HAV}$ infection among working professional aged 25-64 may be of concern for employers. Lack of immunity, which means susceptibility to HAV infection, was found in $46.3 \%$ of persons in a cohort of adults aged 25-64, investigated by the authors of the current study. Although their vaccination status against HA was unknown, in general, the seroprotection rate in the studied group showed that it increases with age. More than $72 \%$ of persons aged 45 and above were immune to HAV, while in groups of persons aged 25-44, susceptibility to HAV infection was lower in the younger age groups.
Such a pattern is typical for countries which have changed from intermediate to low HAV endemicity [10]. A study from the USA indicates an increasing trend towards the hospitalization of new HA cases, together with an increase in the mean age of fatal outcomes [14].

There are 2 main sources of information on HAV infection in a geographical setting: serological surveys indicating past infection and epidemiological surveillance on clinical cases of HA. The first serological survey on anti-HAV in Poland showed that in the population aged over 18, more than $90 \%$ were seropositive in a studied country region [15]. The serological surveys during the following years showed a continuous decrease in seropositive subjects [16, 17]. This was accompanied by shrinking numbers of reported HA cases. At present, it is mandatory to notify all HA cases in Poland, and the National Institute of Public Health (NIPH) in Warsaw is responsible for epidemiological surveillance. At the time period of the current study, a countrywide surveillance on symptomatic HA cases indicated a very low endemicity, similar to other developed countries [10]. During the years of this study (2013, 2014 and 2015), the number of HA cases noted in Poland was 48, 76 and 49, respectively. The incidence per 100,000 inhabitants was $0.12,0.20$ and 0.13 , respectively $[18,19,20]$.

Such an epidemiological situation as that of 2013-2015 continued in 2016, with 35 noted cases of HA, and the incidence of 0.09/100 000 inhabitants. However, in 2017, an unexpected increase in the number of symptomatic HA cases took place, with 3,072 cases and incidence of 7.99/100 000 inhabitants [21]. A similar situation has also been noted in other European countries, mainly affecting groups of MSM [22]. The reasons for the quite rapid increase in the numbers of HA cases in Poland have not yet been fully explained, and epidemiological data are now being analysed at the NIPH. Taking into account the negative scenario, it seems that the modelling of the future incidence of $\mathrm{HA}$ in Poland might resemble that of the USA [14].

Currently, vaccination against $\mathrm{HA}$ in Poland is not obligatory, but recommended at own cost or at the cost of an employer, to 3 groups of people: travelers to endemic regions, people working at the production and distribution of food, or those dealing with communal wastage systems. It is also recommended to pre-school or school children or teenagers who had not been vaccinated previously.

Based on the presented data and on the changing epidemiological situation of HAV infection in Poland, it is suggested that employers might include into their private health insurance portfolio an additional procedure of vaccination against $H A$. At least the most susceptible younger age groups of employees should be included. According to the WHO, just one dose of the vaccine might be sufficient to provide immunity against HAV infection [10].

\section{CONCLUSIONS}

Results of the study show increasing susceptibility to HAV infection in the younger age group of corporate professional employees in large cities in Poland. Nowadays, in order to prevent HA, specific prophylaxis with vaccines is possible. In Poland, vaccination against $\mathrm{HA}$ is recommended and performed at own cost. Since the epidemiological situation of HA is currently changing, it is suggested that employers 
might consider the inclusion of an additional procedure of vaccination against HA into their private health insurance portfolio.

\section{REFERENCES}

1. Lemon SM, Jansen RW, Brown EA. Genetic, antigenic and biological differences between strains of hepatitis A virus. Vaccine. 1992; Suppl 10: S40-S44.

2. Feinstone SM, Kapikian AZ, Purcell RH. Hepatitis A: detection by immune electron microscopy of a viruslike antigen associated with acute illness. Science. 1973; 182: 1026-1028.

3. Ślusarczyk J, Hansson BG, Nordenfelt E, Krawczyński K, Karwowska S, Knap J. Etiopathogenetic Aspects of Hepatitis A. II. Specific and Nonspecific Humoral Immune Response During the Course the Course of Infection. J Med Virol. 1984; 14: 269-276.

4. Seeberg S, Brandberg A, Hermodsson S, Larsson P, Lundgren S. Hospital outbreak of hepatitis A secondary to blood exchange in the baby. Lancet. 1981; 1: 1155-1156.

5. Barbara JAJ, Howell DR, Briggs M, Parry JV. Post-transfusion hepatitis A. Lancet. 1982; 1: 738.

6. Perevoscikovs J, Lenglet A, Lucenko I, Stainerte A, Payne Hallstrom L, Coulombier D. Assessing the risk of a community outbreak of hepatitis A on blood safety in Latvia, 2008. Euro Surveill 2010; 14(3): pii=19092.

7. Tong MJ, Thursby M, Rakela J, McPeak C, Edwards VM, Mosley JW. Studies on the maternal-infant transmission of the viruses which cause acute hepatitis. Gastroenterology. 1981; 80: 999-1004.

8. Mindel A, Tedder R. Hepatitis A in homosexuals. Br Med J (Clin Res Ed). 1981; 282 (6277): 1666.

9. Gossner CM, Severi E. Three simultaneous, food-borne, multi-country outbreaks of hepatitis A virus infection reported in EPIS-FWD in
2013: what does it mean for the European Union? Euro Surveill. 2014; 19(43):pii=20941.

10. WHO position paper on hepatitis A vaccines. Wkly Epidemiol Rec. 2012; 87(28-29): 261-276

11. Feinstone SM, Gust I. Hepatitis A vaccine. In: Vaccines. Ed. Plotkin S, Orenstein W.: $3^{\text {rd }}$ ed. 1999: 650-672.

12. Livni G, Plotkin S, Yuhas Y, Chodik G, Aloni H, Lerman Y, Ashkenazi S. Seroepidemiology of hepatitis A antibodies among children's hospital staff. Pediatr Infect Dis J. 2002; 21(7): 618-622.

13. Keeffe EB. Occupational risk for hepatitis A: a literature-base analysis. J Clin Gastroenterol. 2004; 38(5): 440-448.

14. Ly KN, Klevens RM. Trends in disease and complications of hepatitis A virus infection in the United States, 1999-2011: a new concern for adults. J Infect Dis. 2015; 212: 176-182.

15. Świderska H, Ślusarczyk J. Viral hepatitis type A. Advances in diagnostic and epidemiological studies. Przegl Epidemiol. 1979; XXXIII, 3: 409-417.

16. Polz-Dancewicz M, Policzkiewicz P, Badach Z. Changing epidemiology of hepatitis A virus infection - a comparative study in Central Eastern Poland (1990-1999). Med Sci Monit. 2000; 6(5): 989-993.

17. Janaszek-Seydlitz W, Bucholc B, Wiatrzyk A. The level of antibodies against hepatitis A virus in persons from the Warsaw area. Przegl Epidemiol. 2007; 61: 675-682.

18. Baumann-Popczyk A. Hepatitis A in Poland in 2013. Przegl Epidemiol. 2015; 69: 247-250.

19. Polański P. Hepatitis A in Poland in 2014. Przegl Epidemiol. 2016; 70(2): 225-230.

20. Polański P. Hepatitis A in Poland in 2015. Przegl Epidemiol. 2017, 71(3): 345-349.

21. Personal communication with I. Paradowska-Stankiewicz Ph. D., the national consultant for epidemiology in Poland. 20/02/2018.

22. ECDC. Communicable Disease Threats Report. Week 1, 31 December 2017 - 6 January 2018. Available at: https://ecdc.europa.eu/sites/portal/ files/documents/communicable-disease-threats-report-06-jan-2018. pdf. 